\title{
Mass wear application of cooperated elements for evaluation of friction pair components condition
}

\author{
Maciej Matuszewski ${ }^{*}$, Małgorzata Słomion ${ }^{1}$, Adam Mazurkiewicz ${ }^{2}$ and Andrzej \\ Wojciechowski ${ }^{3}$ \\ ${ }^{1}$ Bydgoszcz University of Science and Technology, Faculty of Management, Fordońska 430 Street, 85 - \\ 790 Bydgoszcz, Poland \\ ${ }^{2}$ Bydgoszcz University of Science and Technology, Faculty of Mechanical Engineering, Kaliskiego 7 \\ Avenue, 85-796 Bydgoszcz, Poland \\ ${ }^{3}$ ODEKA - Staff Improvement Center SIMP, Toruńska 286 Street 286, 85-880 Bydgoszcz, Poland
}

\begin{abstract}
In this study, the influence of the geometrical surface structure shape on wear process of friction pairs elements with conformal contact was analyzed. Characteristics of the machine elements surface layer were described with special distinction of importance of the surface structure directivity and isotropy in terms of the surface layer transformation. This work presents the results of experimental tests in which the following input factors were used: specimen and counter-specimen ridge angle of intersection $\left(0^{\circ} ; 30^{\circ} ; 45^{\circ} ; 60^{\circ} ; 90^{\circ}\right)$ and specimen and counter-specimen clamp $(1.0 ; 1.5 ; 2.0 \mathrm{MPa})$. The changes of the surface layer were recorded as a function of a specimen mass changes. Based on the conducted research, it was found that the ridge angle of intersection on the specimen and counterspecimen has a significant impact on the wear process intensity. The changes were uttermost for $0^{\circ}$ angle and slightest for $90^{\circ}$. It was also found that the observed changes have a larger gradient for higher specimen load values. Thus, the significance of the geometrical surface structure directivity influence on the friction pair elements wear process intensity was confirmed.
\end{abstract}

\section{Introduction}

The durability and reliability of cooperated machine elements are closely related to the surface layer characteristics because the frictional processes lead to wear and damage and mainly affect this layer. Due to the fact that the surface layer condition significantly affects the machine elements operational features it has become the subject of researcher's interest, as well as the subject of numerous experimental studies. The aim of these studies was to acquire and spread the knowledge of the obtained surface properties and their influence on the kinematic pairs tribological characteristics. The knowledge obtained from these tests makes possible to impart features to the surface layers that increase its resistance to the destructive effects of excitations during machines and devices operation [1-8].

\footnotetext{
*Corresponding author: matus@pbs.edu.pl
} 
The assessment of the current cooperating machine elements condition is important due to the proper functioning of machines and devices.

The purpose of the research described in this paper was to verify the significance of the geometric surface structure directivity for course and effects of the surface layer operational transformation of friction pair elements with conformal contact.

\section{Features of surface layer and wear process}

The surface layer characteristics (stress, hardness, structure, etc.) in the various phases of the product's existence are not constant but are constantly changing. During the implementation of the manufacturing process, the surface layer features, called at this stage the technological surface layer are dynamic, because they change practically after each operation or technological treatment. These changes concern both the interior and top of the surface layer, and the whole process is called the transformation of the technological surface layer. However, because the functional features of the kinematic pairs elements are determined by surface layer condition after technological process last operation, it is this condition that is assumed to be the technological surface layer of the finished element and in such an approach it has a static character [9-13].

From the commencement of the technical object operation process begins, i.e., from the time when it and its components begin to be influenced by external forces, the technological surface layer transforms into operating surface layer and the process of its transformation begins, which, like in case of technological surface layer transformation, is a dynamic process. The condition of the operating surface layer changes throughout its usage phase. The common feature of the transformation of technological surface layer and operating surface layer is therefore the dynamic character of this phenomenon. In case of technological surface layer, due to the course of operation, the state at the end of the manufacturing stage is important, while for the operating surface layer its current state is important [14-16].

Features of the surface layer are greatly determined by the surface stereometry. The stereometric surface shape is defined as the geometrical surface structure. It is a set of surface micro-inequalities that are treatment marks or the effects of the wear process. The basic parameters describe geometrical surface structure are roughness, waviness, degree of surface isotropy - directionality of machining traces, shape deviations and surface defects $[17,18]$.

The parameters that describe the geometrical surface structure i.e., roughness and directivity have an influence on cooperating machine elements surfaces tribological characteristics [9, 19-22].

To describe the condition and changes in the surface layer, various roughness parameters are usually adopted, e.g. $[17,18,23]$. The directivity parameters of the geometric structure of the surface are used less frequently for this purpose. On the other hand, treatment ridges are an inherent result of the manufacturing process. They may have different dimensions, shape and arrangement; therefore, they significantly characterize the condition of the surface layer. It is possible to concluded that for wear process, an important element of the geometric surface structure is also its directionality. This applies especially to kinematic pairs with conformal contact surfaces of the cooperating kinematic pairs elements [24, 25].

\section{Experimental tests}

\subsection{Purpose and research methodology}

The conducted research was aimed at determining the impact of the distribution and orientation of the traces after machining on the cooperating elements at conformal contact on 
the wear intensity. As a measure of the surface layer transformation process, the change (loss) in mass was adopted, i.e. the value that is used as a direct wear measure (mass wear).

The specimens with anisotropic geometric surface structure and clear orientation of the treatment were accepted for the tests (fig. 1). The wear course was observed by changing the relative location of the treatment ridges, thus obtaining the angle of cooperating structures resulting from the characteristic directivity lines. In addition, the relationship between the specimen's mass loss and the degree of their isotropy as well as the friction path for various angular associations of characteristic machining traces was determined. The degree of surface isotropy as a quantitative parameter may be determined from the surface frequency functions. It denotes the degree of orientation - arrangement - of machining ridges or wear.

a.

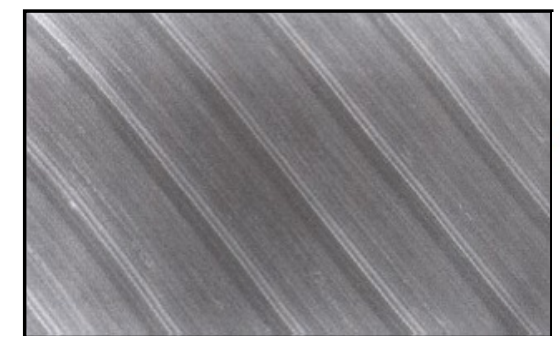

b.

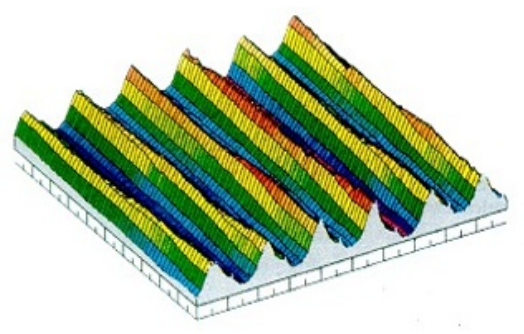

Fig.1. The geometric surface structure of the tested specimens: a. 2D system, b. 3D system.

Samples with such a geometric surface structure were subjected to tribological tests. In these tests, specimens made of $102 \mathrm{Cr} 6$ steel were used, and a counter-specimen- made of $\mathrm{X} 210 \mathrm{Cr} 12$ steel. The specimens with the counter-specimen cooperated on the designed and constructed stand for wear tests.

The hardness of the counter-specimen exceeded (by 50\%) the hardness of the specimens, so the changes that took place mainly on the specimens surface. The hardness values were $60 \mathrm{HRC}$ and $40 \mathrm{HRC}$, respectively.

The specimens with the counter-specimen were co-operated in the lubricating medium, which was machine oil ( $\mathrm{L}-\mathrm{AN} 68)$, at the following values of operating quantities:

- relative motion speed: $2.9 \mathrm{~m} / \mathrm{min}(0.05 \mathrm{~m} / \mathrm{s})$,

- load: 300,450 and $600 \mathrm{~N}$ (corresponding to the theoretical pressures in the contact zone: $1.0,1.5$ and $2.0 \mathrm{MPa}$, respectively).

The research was carried out for the following angular associations between the characteristic traces after treatment: $0^{\circ}, 30^{\circ}, 45^{\circ}, 60^{\circ}$ and $90^{\circ}$.

The principle of selecting the specimens and the counter-specimen during tests and resulting angles between the directionality of the interacting surfaces during tests are presented in fig. 2 .

Tested specimens were immobilised in three grooves located on the setting sleeve positioned on the circumference at every $120^{\circ}$. Oscillating relative movement was performed by the counter-specimen. The counter-specimen clamp to the samples (load on the system) is carried out by tensioning the spring. 


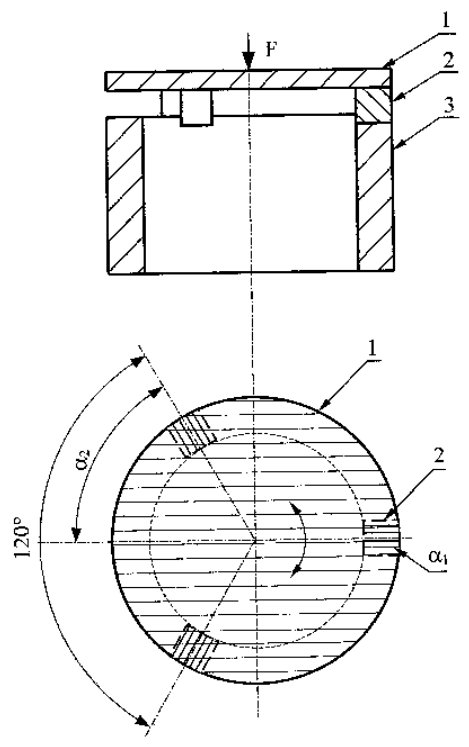

Fig. 2. Selection of the specimens and the counter-specimen depending on $\alpha$ angle $\left(\alpha_{1}=0^{\circ}\right.$ and $\alpha_{2}=$ $60^{\circ}$ ) of tool marks intersection: 1 - specimens; 2 - counter-specimen; 3 - specimen setting sleeve.

\subsection{Experimental tests result}

The results of the experimental research are presented in the form of graphs - Figs. 3 and 4. In Figure 3, the specimens mass changes were caused by the geometric surface structure changes and are presented as a function of the friction path. On the other hand, figure 4 shows the relationship between the specimen's mass loss, the degree of their isotropy and the friction path for various angular associations of characteristic machining traces. During the tests the specimens mass change was determined by weighing them with an analytical laboratory balance WAX 220 with an accuracy of 0.01 milligram.

a.

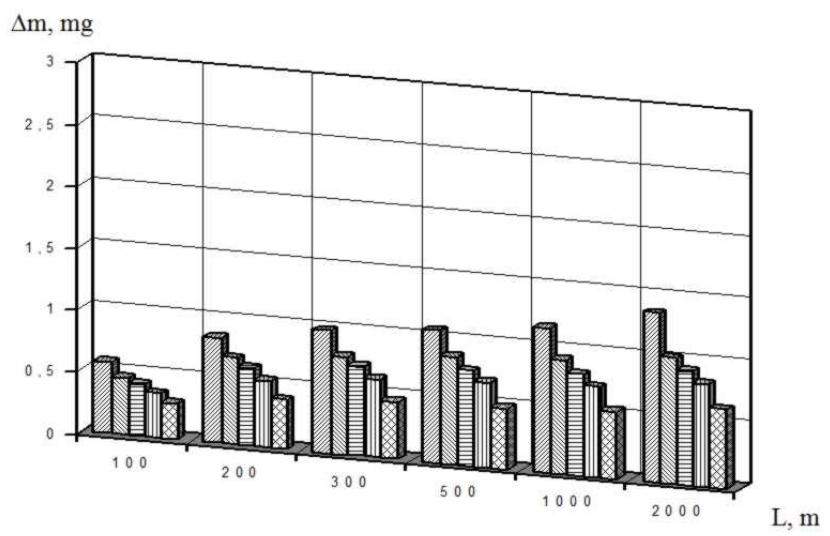


b. $\Delta \mathrm{m}, \mathrm{mg}$

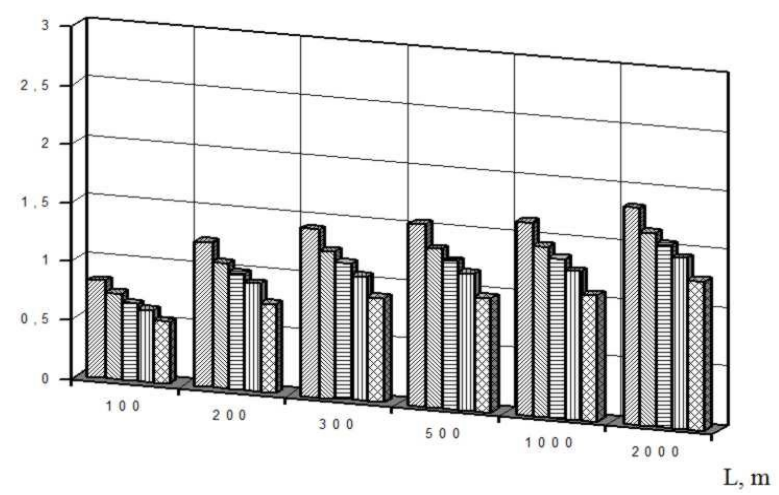

c.

$\Delta \mathrm{m}, \mathrm{mg}$

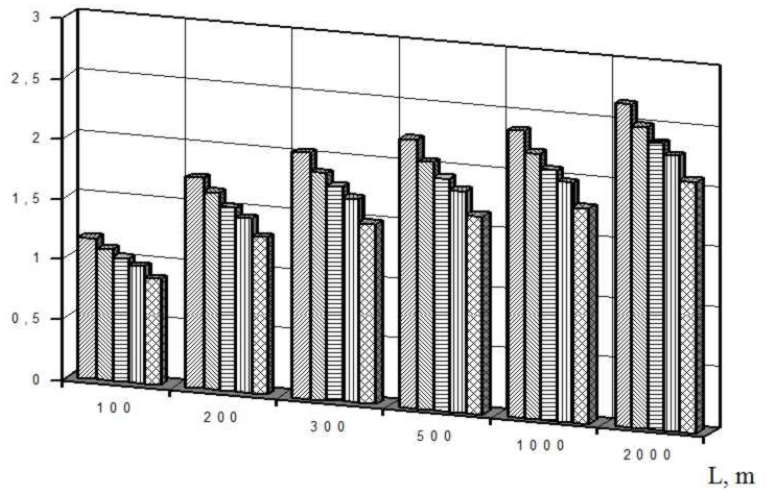

$$
\begin{aligned}
& \alpha_{1}=0^{\circ} ; \mathbb{N} \alpha_{2}=30^{\circ} ; \text { 伺 } \alpha_{3}=45^{\circ} ; \\
& \alpha_{4}=60^{\circ} ; \\
& \alpha_{5}=90^{\circ}
\end{aligned}
$$

Fig.3. Specimens mass changes $\Delta \mathrm{m}$ as an function of the friction path.

a.

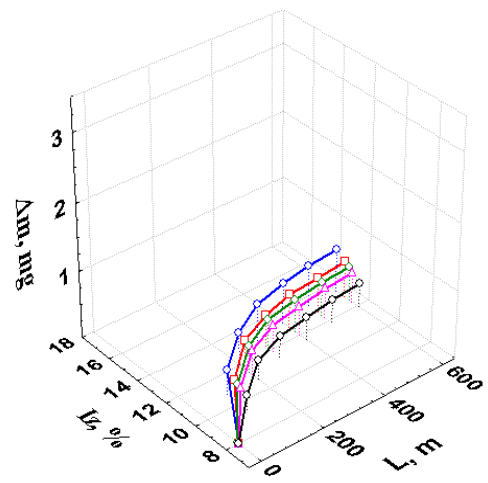

b. 


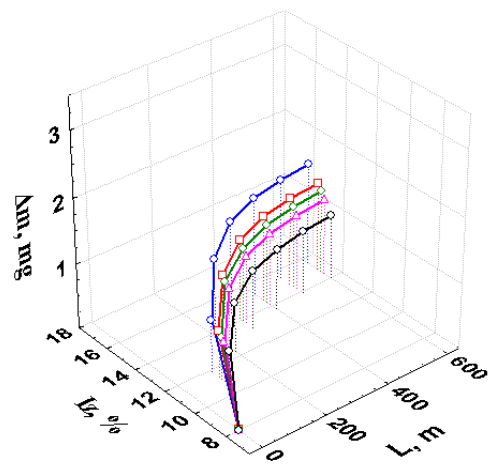

c.

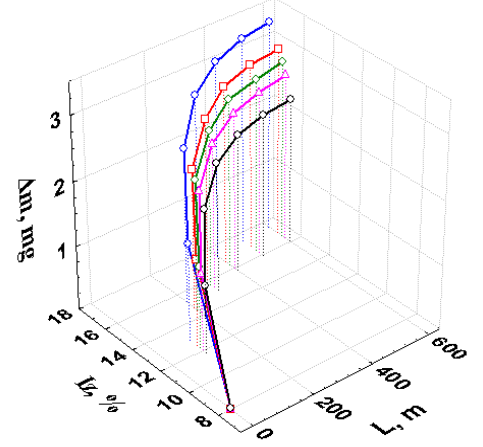

$$
\longrightarrow \alpha_{1}=0^{\circ} \longrightarrow \alpha_{2}=30^{\circ} \longrightarrow \alpha_{3}=45^{\circ} \longrightarrow \alpha_{4}=60^{\circ}-\alpha_{5}=90^{\circ}
$$

Fig.4. Relationships between specimen's mass loss $\Delta \mathrm{m}$, the isotropy degree Iz and the friction path $\mathrm{L}$ for various angular associations of characteristic machining traces for the following pressure forces: $\mathrm{a}$. $300 \mathrm{~N}$, b. $450 \mathrm{~N}$, c. $600 \mathrm{~N}$.

The research indicates that the specimens mass changes, i.e., the parameter describes the wear process intensity, are dependent on the mating angle value of the characteristic machining traces on the cooperating elements surfaces.

It may be observed in the graphs that for the angle $\alpha=0^{\circ}$, the greatest mass loss occurs in relation to the initial mass, and it is accompanied by the most intense increase in the geometrical surface structure isotropy degree. However, for the angle $\alpha=90^{\circ}$, these changes are opposite - the mass loss is the lowest with the low changes in the isotropy degree. On the other hand, the mass changes for intermediate angles, i.e., $30^{\circ}, 45^{\circ}$ and $60^{\circ}$, are always between the values of these quantities for the angles $0^{\circ}$ and $90^{\circ}$. The nature of these changes is that with an angle $\alpha$ increase, both the mass change and the isotropy degree decrease. This may be explained by the fact that at the $0^{\circ}$ angle (the traces are parallel), the microinequalities "stick" to each other and then the material losses as a result of abrasion and shearing are the highest. At $90^{\circ}$ angle (the traces are perpendicular), cooperating surfaces slide each other over the machining traces peaks, there are favorable lubrication conditions and therefore low resistance, which in turn translates into smaller losses of material.

Such a nature of changes is observed for all the realized cooperation conditions (different loads), but for a greater load, the changes in the values of the quantities describing the wear course are more intense. Based on that, it may be concluded in addition to verifying the basic assumption of the research, which is to show that the directivity of the surface structure has 
an impact on the transformation process of the surface layer, it was also confirmed that the wear intensity also depends on the analyzed conditions of cooperated elements.

\section{Summary}

Based on the conducted experimental tests, it was confirmed that the wear process significantly depends on the surface structure directionality, and thus on the structure isotropy degree, it was also found that the wear process intensity depends on the cooperating elements conditions. The cooperating elements mass loss of the friction pair depends on the shape of their geometrical surface structure and cooperation angle of the characteristic traces after machining.

Due to the fact that the influence of the surface stereometry described by the directivity parameters on the course and effects of the operation surface layer transformation has been confirmed, it is advisable to continue the research by extending the sets of input factors with structures with different isotropy degrees.

The test results will make it possible to select the optimal (with tribological criteria) treatment method with regard to the distribution of traces after treatment, and thus to obtain the desired surface stereometry.

\section{References:}

1. A. Dykha, S. Matyukh, T. Kałaczyński, Diagnostics - Experimental Analysis of Friction Pairs at Stick - Slip Sliding. Matec Web of Conferences, 302, 1-8 (2019)

2. I. M. Hutchings, Tribology. Friction and wear of engineering materials, (Elsevier, Cambridge, 1992)

3. T. Kałaczyński, R.M. Martinod, State of mechanical condition applied to industrial machines based on SVD method. Ingeniare. Revista chilena de ingenieria, 26, 264-272 (2018)

4. J. Krawczyk, Tribological properties of selected structural steels (Właściwości tribologiczne wybranych stali konstrukcyjnych). Tribologia, 4, 223-233 (2010)

5. M. Liss, T. Kałaczyński, N. Dluhunovych, A. Dykha, R.M. Martinod, Identification of loads of the construction of a Hybrid Multimedia Mobile Stage. Matec Web of Conferences, 332, 1-9 (2021)

6. M. Madej, D. Ozimina, K. Kurzydłowski, T. Płociński, P. Wieciński, M. StypRekowski, M. Matuszewski, Properties of diamond-like carbon coatings deposited on CoCrMo alloys. Transactions of Famena, 39, 79-88 (2015)

7. V. Martynyuk, O. Eromenko, J. Boiko, T. Kałaczyński, Diagnostics of supercapacitors. Matec Web of Conferences, 182, 1-10 (2018)

8. M. Styp-Rekowski, E. Mańka, M. Matuszewski, M. Madej, D. Ozimina, Tribological problems in shaft hoist ropes wear process. Industrial Lubrication and Tribology, 67, 1, 47-51 (2015)

9. T. Burakowski, The importance of surface engineering in tribology (Znaczenie inżynierii powierzchni $w$ tribologii). Tribologia, 4, 1097-1111 (2002)

10. J. H. Horng, J. F. Lin, K. Y. Li, Effect of surface roughness on stell roller scuffing. Wear, 184, 203-212 (1995)

11. W. Lubimow, K. E. Oczoś, Selected issues of shaping surface irregularities in machining processes (Wybrane zagadnienia kształtowania nierówności powierzchni w procesach obróbkowych). Mechanik, 3, 81-84 (1997)

12. J. Raja, Field testing of machine tool diagnostic techniques using surface metrology. Annals of CIRP, 32, 503-506 (1983) 
13. D. J. Whitehouse, Process and quality control using surface finish. Proceedings $6^{\text {th }}$ Symposium IMEKO Metrology for quality control in production, Vienna, 699-710 (1998)

14. T. Burakowski, T. Wierzchoń, Metal surface engineering (Inżynieria powierzchni metali), (Publ. WNT, Warszawa, 1995)

15. E. Mańka, M. Styp-Rekowski, M. Matuszewski, D. Y. Pimenov, Shaft hoist rope wear condition as a diagnostics signal. Matec Web of Conferences, 332, 1-10 (2021)

16. G. W. Stachowiak, A. W. Batchelor, Engineering tribology, (Butterworth-Heinemann, Great Britain, 2001)

17. R. Górecka, Z. Polański, Metrology of the surface layer (Metrologia warstwy wierzchniej), (Publ. WNT, Warszawa 1983)

18. K. E. Oczoś, W. Lubimow, Surface geometric structure (Struktura geometryczna powierzchni), (Publ. Rzeszow University of Technology, Rzeszów, 2003)

19. P. Pawlus, Surface topography: measurement, analysis, impact (Topografia powierzchni: pomiar, analiza, oddziatywanie), (Publ. Rzeszow University of Technology, Rzeszów, 2006)

20. B. Nowicki B., Geometric structure: surface roughness and waviness (Struktura geometryczna: chropowatość i falistość powierzchni), (Publ. WNT, Warszawa, 1991)

21. B. G. Rosen, R. Ohlsson, J. Westberg, 1995. Interactive surface modelling, an implementation of an expert system for specification of surface roughness and topography. International Journal of Machine Tools and Manufacture, 35, 317-324 (1995)

22. K. E. Oczoś, W. Lubimow, Determinism and randomness of surface geometric structures (Determinowość i losowość struktur geometrycznych powierzchni (SGP)). Pomiary Automatyka Kontrolna, 10, 2002, 4-6 (2002)

23. M. Wieczorowski, A. Cellary, J. Chajda, A guide to measuring surface roughness, or roughness and more (Przewodnik po pomiarach nierówności powierzchni czyli o chropowatości i nie tylko). (Publ. Poznan University of Technology, Poznań, 2003)

24. M. Matuszewski, M. Słomion, A. Mazurkiewicz, D.Y. Pimenov, Assessment of friction pair elements condition based on changes in the geometric surface structure isotropicity degree. Matec Web of Conferences, 302, 1-8 (2019)

25. J. Williams, Engineering tribology, (Cambridge University Press, Cambridge, 2005) 